\title{
O tutor em Educação a Distância: análise ergonômica das interfaces mediadoras ${ }^{1}$
}

\author{
The tutor in Distance Learning: \\ ergonomic analysis of mediating interfaces
}

\author{
Maurício Miranda Sarmet ${ }^{2}$ \\ Júlia Issy Abrahão ${ }^{3}$
}

\section{RESUMO}

$\mathrm{Na}$ Educação a Distância (EaD), o processo pedagógico pode ser mediado por aplicativos informatizados, muitas vezes utilizando a Internet como via de acesso. Essa mediação contribui para o aprimoramento da relação ensino-aprendizagem e estrutura o papel dos diferentes atores dessa relação. O objetivo do presente estudo é investigar o impacto do uso de ferramentas informatizadas na atividade dos tutores de cursos via Internet. A amostra foi composta por 4 tutores, com características distintas. Utilizou-se a Análise Ergonômica do Trabalho e foram realizadas entrevistas, análises de interação e observações, o que permitiu a elaboração de uma crônica da atividade dos tutores. Os resultados apontam a incerteza e variabilidade das demandas dos alunos e o impacto das ferramentas informatizadas na atividade. Discute-se a necessidade de compreender quem é o tutor na $\mathrm{EaD}$, fornecendo parâmetros para a concepção de ferramentas que facilitem o trabalho.

Palavras-Chave: Ergonomia cognitiva; Tarefas cognitivas complexas; Educação a distância; Sistema informatizado; Tutor.

1 O presente trabalho é resultante do mestrado realizado no Instituto de Psicologia da Universidade de Brasília, com apoio do CNPq.

2 Doutorando em Psicologia Social do Trabalho e das Organizações (PSTO), Universidade de Brasília.msarmet@gmail.com.

3 Professora do Programa de Pós-graduação em Psicologia Social, do Trabalho e das Organizações (PSTO) da Universidade de Brasília. abrahao@unb.br. 


\section{ABSTRACT}

In Distance Learning, the educational process can be mediated by digital systems, often using Internet as access medium. This mediation contributes to the enhancement of the teaching-learning relationship and structures the role of the different actors in it. This study's goal is investigating the impact of the use of digital tools in tutors' activities in online courses. The sample was defined by 4 tutors with distinct characteristics. Work Ergonomic Analysis was used, and interviews, interaction analysis and observations were made, which allowed the creation of a chronicle about the tutors' activities. The results points to the uncertainty and variability of the student's demands and the impact of the digital tools on the activity. The necessity of comprehending the tutor's role in D.L., giving parameters to the concept of tools that facilitate the work, is discussed.

Keywords: Cognitive ergonomics; Cognitive tasks; Distance Learning; Digital systems; Tutor.

\section{INTRODUÇÃO}

Nos últimos anos, a educação vem passando por uma fase expressiva de mudanças. O papel do professor, a metodologia de ensino e até mesmo a função da escola têm sido objeto de discussão no mundo inteiro (Marinho, 2002; Morin, 2001; Perrenoud, 2000; Pretto, 2001; Ramal, 2002). As mudanças na sociedade e na forma como ela se relaciona com seus integrantes e com o sistema produtivo solicitam reflexões sobre como o ensino deve ser estruturado. Nesse sentido, as inovações tecnológicas (principalmente os sistemas informatizados e a Internet) e a sua inserção no cotidiano da sociedade assumem um papel cada vez mais importante. Rasmussem (2000) afirma que a sociedade torna-se mais dinâmica e integrada em função do uso intensivo dessas tecnologias, acarretando mudanças expressivas nas diversas formas de produção humana. O processo de desenvolvimento tecnológico e social passa a nortear a visão, as formas e as estratégias de transmissão de 
informações e conhecimentos (Belloni, 1999). Nesse contexto, as novas tecnologias começam a ser analisadas enquanto ferramentas úteis à educação, contribuindo efetivamente para o aprimoramento das relações de ensino e aprendizagem.

A Educação à Distância - EaD - é uma modalidade que tem buscado conciliar o uso das tecnologias ao processo educacional, com o intuito de ampliar a possibilidade de educação (Litwin, 2001). Os métodos de EaD adotam o envio por correspondência do material de ensino, o rádio, a televisão, o computador e atualmente a Internet como veículo mediador da transmissão de conhecimentos, criando um meio de comunicação cujas possibilidades dependem da tecnologia utilizada e do planejamento da Instituição (Belloni, 1999; Maia, 2002).

Diferentes disciplinas têm pesquisado a Educação a Distância tais como a Psicologia, a Educação e a Informática. A Ergonomia pode contribuir nesse processo uma vez que busca compreender, a partir da análise das situações reais, como se dá a relação entre o indivíduo (com suas necessidades e características) e o sistema de trabalho. $\mathrm{O}$ foco da Ergonomia tem como centro o usuário e parte de um corpo interdisciplinar de conhecimentos (Abrahão, 1993). Assim, no caso dos sistemas informatizados de apoio à $\mathrm{EaD}$, pela via da Ergonomia procurase apreender as condições em que se dá a interação entre o indivíduo e esses artefatos de trabalho, as estratégias utilizadas na navegação e na resolução de possíveis problemas. Atualmente, há o interesse em se analisar a adequação dos artefatos informatizados e seu impacto na realização de determinadas atividades. Apesar disso, Shackel (2000) ressalta a escassez de estudos que relacionam a Ergonomia à EaD. Essa realidade evidencia a relevância em se produzir conhecimentos específicos sobre essa área, principalmente considerando o papel da interface informatizada enquanto instrumento de mediação entre o professor e os alunos. 
Dentro do contexto da Educação a Distância, evidencia-se uma discussão sobre o papel docente: quais são suas atribuições e características, o que se altera no seu fazer e como ele lida com as novas tecnologias educativas, entre outros aspectos. O presente estudo tem como foco a relação do tutor com essas ferramentas. Dito de outra forma, busca-se analisar, sob a ótica da Ergonomia Cognitiva, o impacto do uso de ferramentas informatizadas na atividade dos tutores de uma instituição que oferece cursos de EaD. Ele se inicia pela apresentação das principais características da $\mathrm{EaD}$, de uma breve discussão sobre a figura do tutor e dos principais conceitos oriundos da Ergonomia Cognitiva. Em seguida, são descritos os aspectos metodológicos e os principais resultados da análise da atividade de tutores, buscando, a partir do referencial apresentado, responder às seguintes questões: 1) qual é o impacto, do ponto de vista cognitivo, das características das interfaces informatizadas no trabalho do tutor?; 2) quais são as estratégias elaboradas pelos tutores para navegar nas interfaces informatizadas?; e 3) como a análise da atividade pode contribuir para a melhorar as condições de trabalho dos tutores e a qualidade das ferramentas disponibilizadas?

\section{O trabalho do tutor e suas características na EaD}

As tarefas do docente a distância são divididas em três grandes grupos: a) tarefas de concepção e realização dos cursos e materiais; b) planejamento e organização da distribuição dos materiais e da administração acadêmica; e c) acompanhamento do estudante. O docente na EaD passa a ter funções de criador, formador e realizador de cursos e materiais, pesquisador, tutor, "tecnólogo educacional" e monitor (Belloni, 1999). A tutoria, portanto, se apresenta como uma das funções que o professor a distância passa a assumir.

Ao tutor, na opinião de Maggio (2001), é atribuída a função de orientar o processo de aprendizagem dos alunos, assegurando o 
cumprimento dos objetivos de ensino. Ele deve propor atividades e auxiliar na sua resolução, sugerindo - quando necessário - fontes adicionais de informação. Complementando o perfil dos tutores, Maia (2002) inclui entre as habilidades solicitada aos tutores a competência tecnológica, assiduidade no feedback, capacidade de gerenciamento de equipes e gestão de pessoas, domínio sobre o conteúdo e competências de comunicação e de mediação.

Ao tutor, enfim, não basta o conhecimento do conteúdo a ser ensinado; é necessário que ele seja portador de competências de gestão de equipes e do processo de aprendizagem, e ainda detenha conhecimento das técnicas e dos recursos mais adequados a cada evento de ensino. Esses requisitos assumem um caráter paradoxal, considerando a figura coletiva do professor apontada por Belloni (1999): ao mesmo tempo que suas atribuições são disseminadas em uma equipe interdisciplinar (conteudistas, web designers, programadores, entre outros), é necessário que ele tenha competências de gerência do todo no processo de ensino.

Belloni (1999), em sua revisão, constata que a definição da EaD é construída a partir da descrição das suas principais características. Elas são analisadas à luz de suas semelhanças e dissimilitudes com o ensino presencial convencional. A autora os sintetiza e ressalta como características: a) distância entre professor e aluno (Coiçaud, 2001); b) ruptura temporal do processo de educação (Belloni, 1999; Litwin, 2001; Maia, 2002); c) mediação por um aparato tecnológico (Belloni, 1999; Litwin, 2001; Mercer; Estepa, 2001); d) flexibilidade na estruturação dos conteúdos e utilização de recursos tecnológicos (Belloni, 1999); e) ênfase na autonomia do aluno enquanto gestor do seu processo de aprendizagem, e; f) mudanças administrativas e organizacionais (Belloni, 1999). Essas definições ressaltam tanto a mediação da relação de educação por artefatos tecnológicos quanto uma mudança no papel dos seus atores nesse novo cenário. Tal mudança, segundo Perrenoud (2000), ocorre, 
sobretudo, graças às ferramentas disponíveis, aos avanços na teoria sobre educação, aprendizagem e pedagogia, e em função das demandas da sociedade. As novas tecnologias acabam por nortear a forma como o conhecimento é produzido e transmitido.

Considerando esse cenário, o papel do tutor ainda carece de análise mais aprofundada, bem como as exigências que tal cargo comporta. Com o intuito de compreender quais são as atividades dos tutores na organização estudada, suas ferramentas e sua dinâmica de trabalho, adotou-se como referencial teórico e metodológico a Ergonomia da atividade, devido aos pressupostos que ela comporta e a fineza dos dados que se pode obter por meio de sua metodologia.

\section{Os conceitos usuais em Ergonomia Cognitiva}

O Objeto da Ergonomia é o trabalho que, segundo Hollnagel (1997), pode ser entendido como uma atividade física e mental voltada para a produção ou realização de algo. Essa definição associa à Ergonomia um caráter essencialmente aplicado: ela nasce para responder a uma demanda específica, e avança conforme evoluem as situações e a atividade humana no trabalho. $\mathrm{O}$ trabalho deve ser compreendido pela análise da dicotomia entre o prescrito e o real, uma vez que o primeiro não é o bastante para a compreensão da situação de trabalho (Ferreira, 2000; Guérin et al., 2001; Montmollin, 1990). Em função disso, a análise da atividade dos trabalhadores tem papel norteador na ação ergonômica, delimitando os instrumentos e procedimentos mais adequados (Abrahão; Pinho, 1999; Guérin et al., 2001).

Em Ergonomia se compreende que a relação entre o homem e seu trabalho se dá em três dimensões de análise - física, cognitiva e psíquica. A Ergonomia Cognitiva - EC - pode ser entendida como uma disciplina que estuda os aspectos cognitivos e de conduta na inter-relação entre o homem e os elementos do trabalho, mediada pela utilização de 
artefatos (Cañas; Waerns, 2001). Seu papel, entre outros, é compatibilizar as soluções tecnológicas às características e necessidades dos usuários (Marmaras; Kontogiannis, 2001), por meio de uma análise focada em um contexto específico. Em suma, pela EC busca-se compreender como o indivíduo gerencia a situação de trabalho a partir das informações que recebe: o aparato cognitivo humano não é capaz de tratar todas as informações disponíveis e, em função disso, dispõe de um sistema de seleção e otimização de seus recursos (Sternberg, 2000).

\subsection{As competências}

Um dos principais conceitos utilizados pela EC para compreender como ocorre essa gestão é o de competências. Montmollin (1990) compreende as competências como sendo a articulação entre conhecimentos (declarativos e procedimentais), representações, tipos de raciocínios e estratégias cognitivas que o sujeito constrói e modifica no decorrer de sua atividade. A competência é inerente a todos os indivíduos e não está necessariamente, na opinião do autor, associada a uma noção de excelência no desempenho (Montmollin, 1995). Leplat (1991), por sua vez, aponta que as competências se constroem e se desenvolvem em função das experiências do indivíduo em executar uma tarefa específica. É por meio dessas competências que são capazes de realizar suas tarefas, e principalmente antecipar os possíveis erros e disfuncionamentos e de aprimorar seus procedimentos de trabalho (Montmollin, 1986).

Pode-se dizer, assim, que as competências refletem como o indivíduo utiliza seus recursos cognitivos (conhecimentos, experiências, estratégias) ao solucionar uma situação-problema em seu contexto (Marmaras; Pavard, 1999; Marmaras; Kontogiannis, 2001). De acordo com Silvino e Abrahão (2003), Silvino (2004) e Abrahão, Silvino e Sarmet (2005), o conceito de competências se fundamenta na relação entre as representações para ação e as estratégias operatórias. 


\subsection{As representações para ação}

As representações constituem um dos meios de armazenar as informações sobre o mundo, sejam elas na forma de modelos mentais, esquemas e scripts, dependendo da especificidade da informação armazenada. As representações não comportam todos os elementos de uma situação, só os mais relevantes para o planejamento de ações e a resolução de problemas (Amalberti, 1991), permitindo melhor gestão dos recursos cognitivos.

As representações, segundo Teiger (1993), são construídas a partir da interação do indivíduo com o contexto que o cerca, com um objetivo específico. É por meio dos resultados da ação que as representações são definidas e modificadas, em função de alterações na natureza, nas condições e na organização do trabalho (Weill-Fassina et al., 1993). Da mesma forma, as representações determinam a seleção das informações relevantes e dos procedimentos mais adequados para se realizar uma tarefa (Teiger, 1993). Os mesmos autores descrevem as representações como construtos dinâmicos, flexíveis e adaptativos na medida em que são utilizados em situações distintas.

As representações podem ser entendidas como o resultado de um processo de memória que pressupõe a codificação da informação, seu armazenamento e sua posterior evocação (Cañas; Waerns, 2001; Sarmet, 2003; Silvino, 2004; Abrahão; Silvino; Sarmet, 2005). Nesse sentido, as representações são construídas e organizadas na forma de uma rede semântica, em que cada um dos pontos dessa rede se encontra ligado a outros em função da força e da freqüência dessas relações (Anderson, 1993). A cada estímulo exterior apresentado, ativa-se um padrão, (re)criando o produto da memória de trabalho ou seja, as representações, com base em seus elementos fundamentais. Pela apreensão das representações e dos elementos relevantes da situação de trabalho, é possível estruturar sistemas informatizados mais eficientes e eficazes, 
fornecendo ao usuário pistas claras que indiquem as possibilidades mais adequadas de ação, favorecendo a elaboração de estratégias operatórias que permitem antecipar disfuncionamentos e propor soluções efetivas, concretizadas por meio dos modos operatórios.

\subsection{Estratégias e modos operatórios}

As estratégias operatórias podem ser entendidas como um conjunto ordenado de passos que envolvem o raciocínio e a resolução de problemas, possibilitando a ação (Montmollin, 1995). Silvino e Abrahão (2003) definem as estratégias operatórias como sendo um processo de regulação no qual estão envolvidos mecanismos cognitivos como a categorização, a resolução de problemas e a tomada de decisões. As estratégias resultam da interpretação das informações do ambiente e da utilização de informações, conhecimentos e experiências armazenados na memória do operador e articulados com as informações que o ambiente disponibiliza. Após a definição das estratégias, o indivíduo é capaz de operacionalizar um conjunto de procedimentos para alcançar o objetivo planejado. A esse conjunto de procedimentos dá-se o nome de modos operatórios (Guérin et al., 2001), resultado de uma regulação entre o que deve ser feito, as condições disponíveis para sua execução e o estado interno do trabalhador.

Pelo menos quatro processos cognitivos estão envolvidos na estruturação e utilização (por meio de estratégias e modos operatórios) das representações para ação: a atenção, entendida como o processo que permite a captação e o tratamento consciente de informações (Sternberg, 2000). As teorias sobre atenção buscam explicitar como o ser humano processa determinadas informações em detrimento de outras, e quais as conseqüências para o seu desempenho em determinadas tarefas. Os estudos de Pashler, Johnston e Ruthruff (2001), por exemplo, apontam que o processo de atenção não ocorre somente em função do estímulo apresentado, sem um direcionamento ativo do indivíduo. As 
características dos estímulos do ambiente, no entanto, podem facilitar ou interferir no controle consciente da atenção. A categorização, que permite compreender como as informações percebidas são relacionadas a outras que estão armazenadas na memória (Best, 1995); a memória, processo pelo qual se pode compreender como os conhecimentos são codificados, armazenados e posteriormente recuperados (Best, 1995; Sternberg, 2000); e, por último, a resolução de problemas, que permite compreender como os elementos de uma determinada situação são analisados e como os indivíduos utilizam as informações disponíveis na construção e na resolução de um problema.

A teoria de resolução de problemas de Newell e Simon (1972, apud Sternberg, 2000), por exemplo, compreende a resolução de problemas com um processo que engloba a análise dos elementos do problema e a busca pela estratégia mais adequada de resolução. A representação do espaço do problema, que é construída pelo indivíduo no processo de resolução, está relacionada à clareza das informações disponibilizadas e à experiência do sujeito, e quanto mais correta for essa representação, maior serão as chances de resolução (Keren, 1984). Quando um problema não é bem definido, o indivíduo não é capaz de interpretar, com precisão, como solucionar o problema, quais são as alternativas de ação e os obstáculos existentes (Anderson, 1993; Quesada; Cañas; Antoli, 2000; Quesada; Kintsch; Gomez, 2002).

O objetivo a que se propõe esse estudo sugere que a investigação seja conduzida por meio de um modelo centrado no comportamento dos usuários, e que permita inferir as competências e processos cognitivos envolvidos na interação com o sistema informatizado.

\section{A Trajetória Metodológica}

Utilizou-se no presente estudo o modelo de análise de tarefas cognitivas complexas, proposto por Marmaras e Pavard (1999). Ele tem 
como base a Análise Ergonômica do Trabalho (Guérin et al., 2001), e resguarda seus principais pressupostos: a ênfase na análise de situações reais de trabalho e na participação ativa dos trabalhadores; e a flexibilidade entre as etapas em função das características e da natureza do objeto em análise, sem a definição de um modelo apriorístico (Abrahão; Pinho, 2002).

\subsection{Características da amostra estudada}

A amostra estudada nessa Central de tutoria é composta por 4 tutores (de um total de 5), que trabalham em turnos diferenciados, e cujas características são apresentadas na Tabela 2. Os turnos são de oito horas de trabalho (manhã e tarde ou tarde e noite), com exceção do tutor 4, que trabalha apenas no período noturno. São oferecidos pela escola cursos técnicos relacionados a: a) montagem e manutenção de computadores e redes; b) programação de computadores, e; c) web design. 


\section{TABELA 1}

Descrição dos tutores da Escola estudada em função de dados demográficos

\begin{tabular}{c|c|c|c|c|c|c}
\hline Tutor & Idade & Gênero & Formação & $\begin{array}{c}\text { Tempo } \\
\text { como tutor }\end{array}$ & $\begin{array}{c}\text { Função } \\
\text { anterior }\end{array}$ & $\begin{array}{c}\text { Já foi } \\
\text { tutor? }\end{array}$ \\
\hline 1 & 23 & Masculino & $\begin{array}{c}\text { Processamento } \\
\text { de dados }\end{array}$ & 1 semana & $\begin{array}{c}\text { Suporte de } \\
\text { informática }\end{array}$ & Sim \\
\hline 2 & 25 & Masculino & Economia & 3 meses & $\begin{array}{c}\text { Suporte de } \\
\text { informática }\end{array}$ & Não \\
\hline 3 & 24 & Masculino & $\begin{array}{c}\text { Processamento } \\
\text { de dados }\end{array}$ & 1 ano & $\begin{array}{c}\text { Atendimento } \\
\text { ao usuário }\end{array}$ & Não \\
\hline 4 & & Feminino & $\begin{array}{c}\text { Ciência da } \\
\text { computação }\end{array}$ & 3 anos & $\begin{array}{c}\text { Professora de } \\
\text { informática }\end{array}$ & Não \\
\hline
\end{tabular}

Três entre os quatro tutores têm a área de informática como formação principal; todos exerciam anteriormente cargo relacionado a essa área. Apenas um deles, o mais recente nessa central de tutoria, já havia sido tutor anteriormente. $O$ tutor 4 já havia trabalhado no magistério na modalidade presencial em outro estabelecimento. Com relação ao tempo como tutor especificamente nessa escola, observa-se grande variação, de 1 semana de trabalho até 3 anos, esse último praticamente coincidindo com o tempo de utilização da internet como suporte pedagógico no estabelecimento.

\subsection{Procedimentos e instrumentos}

Este estudo, apesar da reduzida amostra de tutores, encontra sua relevância na profundidade com a qual os dados foram coletados e tratados. Os procedimentos podem ser divididos, de acordo com o referencial utilizado, nas seguintes etapas:

\section{Etapa 1 - Pré-análise}

Coleta de dados sobre o contexto sócio-técnico - teve como objetivo coletar e analisar as informações referentes ao contexto onde se insere o curso estudado. Realizou-se um conjunto de seis entrevistas semi- 
estruturadas com os tutores e chefia além da análise dos documentos e da história da organização. Esses dados possibilitaram obter uma visão dos tutores a partir de seus dados sócio-demográficos, bem como as principais características da sua rotina de trabalho. Permitiram, também, que se estabelecesse um recorte do objeto de estudo, a partir das tarefas mais freqüentes e os aplicativos mais utilizados.

\section{Etapa 2 - Análise Cognitiva}

Análise dos textos do chat público - procedeu-se a análise dos textos de dez turnos de interação no chat público da escola (totalizando 40 horas), com o objetivo de compreender quais são as principais características no processo de interação entre os tutores e alunos e instrutores.

Observações globais, sistemáticas e participantes, análise da lógica de navegação dos tutores - a característica principal dessa etapa foi a análise da atividade de navegação. Por meio dela, foi possível analisar os impactos do desenho das interfaces informatizadas no desempenho dos tutores. As observações Globais (total de oito horas) tiveram como objetivo a compreensão geral do processo de utilização da interface. As observações sistemáticas e participativas (total de 15 horas) visavam analisar as variáveis recortadas anteriormente e compreender como os tutores lidam com elas e com suas implicações na atividade.

Após essa análise, foi possível estruturar como se dá o processo de navegação nesse curso de $\mathrm{EaD}$ e compreender quais são as estratégias e modos operatórios elaborados pelos tutores para realizar a gestão do tempo, as ferramentas e da diversidade de demandas dos usuários. Os dados obtidos nesta etapa permitiram identificar, ainda, as variáveis que compõem a atividade do tutor. 


\section{Resultados e discussão}

Os resultados e a discussão serão apresentados em concomitância, com o intuito de favorecer a articulação dos dados de natureza diferenciada, associando-os aos referenciais teóricos e à trajetória metodológica. Nas páginas subseqüentes, é descrito o contexto de estudo, apresentando as características da organização estudada, as atribuições formais dos tutores e sua rotina na organização, seguida de uma caracterização da sua atividade em função das especificidades encontradas no caso estudado.

\subsection{O contexto de estudo}

A escola estudada possui uma central por meio da qual as atividades são conduzidas via Internet. A sua função é viabilizar o contato virtual entre os alunos, fornecer auxílio por meio do serviço de tutoria e flexibilizar as atividades do curso (cujo conteúdo é disponibilizado em CD-ROM enviado aos alunos), disponibilizar tarefas que comportam desde listas de exercícios até discussões em chats e fóruns, ferramentas que são utilizadas nesse ambiente eletrônico. Pela mesma central, os alunos solicitam declarações e outros documentos e ela é também o meio de contato com a administração do curso.

O sistema informatizado permite controlar o acesso a algumas informações, tais como a data em que o usuário acessou o sistema, sendo que o acesso é restrito segundo a categoria de usuário. Apesar de todas as opções citadas, o sistema ainda é limitado quando se considera as necessidades da organização. Informações sobre tempo de acesso, páginas mais acessadas e os dados pessoais dos alunos não estão disponíveis. A organização utiliza, por exemplo, um arquivo de banco de dados do aplicativo Microsoft Access para gerir os dados cadastrais de todos os seus alunos, bem como as informações referentes à sua situação escolar (denominado de Ficha individual do aluno). 


\subsection{Atribuições formais dos tutores e sua rotina de trabalho}

Todos os tutores, segundo a documentação da escola, recebem as mesmas atribuições. O QUADRO 1 descreve sucintamente as tarefas que lhes são atribuídas pela organização.

\section{QUADRO 1}

\section{Descrição das tarefas dos tutores da Escola}

\section{Tarefa dos tutores}

- Elaborar e manter atualizado o banco de questões de provas das disciplinas;

- Elaborar e enviar atividades das disciplinas aos alunos;

- Corrigir atividades enviadas pelos alunos;

- Esclarecer dúvidas dos alunos, instrutores e responsáveis pelas Escolas Licenciadas;

- Manter o aluno informado sobre sua situação acadêmica;

- Acompanhar o desenvolvimento pedagógico do aluno;

- Analisar e revisar questões e atividades criadas por outros tutores;

- Manter atualizada a Ficha Individual dos alunos;

- Manter-se atualizado em relação aos cursos da Escola e das demais tecnologias do mercado;

- Incentivar a participação dos alunos nos eventos promovidos pela Escola;

- Incentivar a permanência do aluno na Escola;

- Manter a Escola Licenciada informada sobre a situação acadêmica de seus alunos;

- Encaminhar toda e qualquer reclamação de alunos ou instrutores para o departamento competente.

Fonte: documentação da empresa.

As entrevistas realizadas permitem caracterizar a rotina dos tutores: ao chegar, a primeira ação é monitorar o chat público, uma vez que sempre deve haver um tutor disponível para auxiliar um aluno com dúvidas. Quando um aluno entra, sai ou manda alguma mensagem para o tutor, a janela do chat é automaticamente ativada e posicionada à frente das 
outras janelas abertas do computador (denominada nesse estudo de função $p \circ p-u p)$. Essa tarefa é de suma importância e a escola recomenda que os tutores não deixem o aluno sem o devido atendimento. Quando o assunto não é de competência do tutor, ele deve encaminhar o solicitante à pessoa ou ao departamento mais indicado.

A segunda tarefa consiste em verificar os e-mails enviados à Central de Tutoria. As mensagens são de natureza diversificada: dúvidas sobre conteúdo, questões administrativas, envio de atividades pedagógicas e mensagens de cunho social. É determinado pela direção que os tutores respondam as mensagens recebidas pela Central de Tutoria no prazo máximo de quatro horas.

Entre as várias demandas oriundas do correio eletrônico, corrigir os exercícios pedagógicos é uma tarefa, de acordo com os tutores, realizada praticamente todos os dias, e constitui a maior parte das mensagens recebidas por esse meio. $\mathrm{Na}$ sua realização os tutores utilizam: (a) o gerenciador de e-mail, o (b) o programa específico do exercício e a (c) a base de dados no aplicativo Microsoft Access, onde consta a Ficha Individual do aluno, para atribuir a nota.

Outras tarefas comuns são estudar o conteúdo das disciplinas oferecidas pela escola, elaborar os exercícios e roteiros para debates, as aulas virtuais e os fóruns, a construção de bancos de dados e a inserção das questões no sistema informatizado.

As observações globais e as entrevistas com os tutores apontaram a tarefa de monitorar o chat público como a de maior freqüência durante o período de trabalho. A seção a seguir descreve a análise da atividade de monitoração, considerada pelos tutores, e reforçada pelos resultados, como sendo uma das mais relevantes no seu fazer. 


\subsection{A análise da atividade}

O critério de escolha da tarefa a ser observada foi a sua natureza. Como este estudo não tem a pretensão de analisar a diferença entre os diversos tutores, a observação contemplou aqueles que desempenham tarefas relacionadas à monitoração do chat da escola. Nesse caso, em todas as situações analisadas identificou-se uma tarefa concorrente sendo realizada como, por exemplo, a correção de exercícios. Com base na análise documental e nas informações coletadas nas entrevistas, foi possível identificar as variáveis que compõem a atividade, e elas constituíram o objeto das observações.

Com base na avaliação da usabilidade do sistema informatizado apresentada por Sarmet (2003), duas variáveis foram analisadas: a) a alternância de aplicativos, uma vez que o sistema informatizado não é único para todas as tarefas dos tutores, exigindo que eles "pulem" de um aplicativo para outro e; b) ocorrência do $\not \circ p$-иp. Levanta-se a hipótese de que a freqüência de aparecimento dessas variáveis pode elevar a complexidade do trabalho dos tutores. Assim, a análise mais fina desses elementos e a sua influência auxiliam a compreensão da atividade (TAB. 2).

\section{TABELA 2}

Freqüência das variáveis de alternância de telas e pop-up por observação sistemática realizada. Tempo de cada observação: 1 hora

\begin{tabular}{c|c|c}
\hline Observação & Alternância de aplicativos & Função Pop-up \\
\hline Debate & 111 & 14 \\
Debate & 172 & 20 \\
Aula virtual & 149 & 21 \\
Aula virtual & 181 & 21 \\
Aula virtual & 146 & 11 \\
Monitoração & 84 & 19 \\
Monitoração & 102 & 26 \\
Monitoração & 178 & 7 \\
Monitoração & 119 & 5 \\
Monitoração & 29 & 11 \\
Monitoração & 65 & 16 \\
Monitoração & 28 & 3 \\
Monitoração & 55 & 7 \\
Monitoração & 50 & 4 \\
Monitoração & 136 & 14 \\
& &
\end{tabular}


$\mathrm{Na}$ tentativa de verificar se os valores encontrados nas observações diferiam - considerando o tipo de atividade realizada (monitoração ou $c h a t$ ); e o turno -, realizou-se uma série de análises de variância (Manova). Os resultados encontrados não apresentaram diferenças significativas entre os casos. Outros fatores, portanto, devem ser levados em consideração para explicar a variabilidade, como a possibilidade de falhas no sistema e o caráter dinâmico e incerto das demandas dos alunos, que, em última instância, responde pela variabilidade do trabalho do tutor. É pela análise da atividade que se podem identificar os elementos que explicam e justificam a existência ou a ausência de tais dissimilitudes.

Considerando os dados disponíveis, escolheu-se para uma análise mais fina a atividade de monitoração do chat público, devido a sua importância na condução do curso, expressa pelos tutores nas entrevistas, e pela sua freqüência diária. Assim, é relatada a Monitoração do Chat Público e, em seguida, é apresentado um caso ilustrativo da atividade dos tutores, denominado de crônica da atividade.

\section{4 - A atividade de monitoração de alunos no chat público}

A monitoração do chat público não precisa ser realizada de forma ativa. Após entrar no chat público e verificar a ausência de demandas por parte dos alunos, o tutor pode se ocupar de outras tarefas. Quando entra um aluno, instrutor ou um responsável por escola licenciada, o tutor é avisado por meio da ativação da tela do chat sobre o aplicativo que ele estiver utilizando (função $p o p-u p$ ); ele interrompe a sua atividade e inicia outra buscando atender as demandas. Esse procedimento se repete durante toda a jornada de trabalho. Eventualmente, os tutores fazem uma cópia de segurança do texto do chat, com o objetivo de se resguardar caso seja necessário checar os diálogos efetuados com os alunos. 
Cabe ressaltar que o sistema informatizado realiza, automaticamente, uma cópia de segurança do conteúdo do chat. $\mathrm{O}$ arquivo digital disponibilizado não mantém, porém, a formatação do documento original (como cores, tamanho de fontes e formatação dos parágrafos), o que dificulta a busca de informações. Assim, os tutores optam pelo procedimento de selecionar o conteúdo, copiá-lo em um editor de textos, para depois salvar o arquivo; não existe, no chat, um comando específico para salvar as informações. Com isso, acrescenta-se à rotina de trabalho um conjunto de etapas que poderia ser realizado automaticamente, sem a ação explícita dos tutores, caso a compatibilidade entre a cópia de segurança efetuada pelo sistema informatizado e a necessidade dos tutores fosse assegurada.

Os tutores se deparam com a possibilidade de serem interrompidos no meio de execução de uma tarefa, devido à ativação automática da função pop-up. Os resultados mostram um mínimo de três e máximo de 26 interrupções por hora de observação (média de 10,50 e desvio-padrão de 7,82), o que caracteriza a imprevisibilidade da ocorrência desse evento. Embora considerem que essa função prejudica as tarefas que estão realizando, os tutores não vêem possibilidade de eliminá-la, dada a política de se priorizar o atendimento do usuário no chat.

O momento de entrada de um aluno no chat público não pode ser previsto, e não existe uma estratégia que alerte o tutor sobre a interrupção repentina da tarefa em curso. Tal condicionante leva o tutor a alterar o foco da sua atenção da tarefa que está executando (de exigência intelectual), podendo ocasionar retrabalho (ex.: rever o material trabalhado) e erros diversos (ex.: corrigir inadequadamente os exercícios pedagógicos). Há, ainda, o risco de que os elementos da tarefa interferente impliquem na (re)estruturação inadequada das representações para ação necessárias para a execução da tarefa inicial (PASHLER et al., 2001). Tal interferência ocorre em função de uma "suposta" similaridade entre os 
aplicativos: embora os aplicativos aparentemente tenham uma lógica semelhante de navegação (levando à automatização de certos procedimentos), os procedimentos, comandos e atalhos não são os mesmos. Dito de outra forma, quando o tutor está realizando uma ação em um determinado aplicativo e é interrompido pelo chat, ele constrói uma nova representação para responder aos problemas colocados pelos alunos. Isso faz com que ele potencialize a probabilidade de que alguns conhecimentos (declarativos e procedimentais) referentes à navegação e utilização do chat fiquem disponíveis para a utilização do aplicativo que o tutor manipulava na tarefa anterior. Ao retornar a essa tarefa, ele pode encontrar dificuldades, incidentes e cometer erros devido a essa facilidade de recuperação (Best, 1995; Sternberg, 2000; Marmaras; Kontogianis, 2001). Da mesma forma, é exigido do tutor um processo de regulação, no qual os tutores buscam regular a atenção para aumentar a probabilidade de resposta aos estímulos oriundos do chat e reduzir outros tipos de interferências. Nesse sentido, a atenção é entendida como um processo de regulação contínua, conforme apontam os estudos de Pashler et al. (2001), e não estanque, sendo ativada e desligada conforme o estímulo. Mesmo ocorrendo essa regulação, a quantidade de vezes em que ocorre a função pop-up aponta para uma complexificação do trabalho que pode comprometer seu desempenho.

A fim de evitar estas interrupções, os tutores freqüentemente ignoram o $p \circ p-u p$, o que de fato é uma estratégia operatória que visa reduzir o tempo de deslocamento da atenção para o conteúdo do chat, mantendo-se concentrado na tarefa em curso e adiando a resposta ao aluno. Durante as observações essa estratégia foi adotada 56 vezes, ou seja, a 53\% dos casos de pop-up. Esssa estratégia operatória permite que o sujeito mantenha uma representação para ação voltada à atividade principal, reduzindo a interferência de novos estímulos e a conseqüente ativação de outros padrões de conhecimentos na memória de trabalho. A 
validação dessas informações leva a duas situações possíveis: muitas vezes quando os tutores estão realizando uma atividade preferem não responder imediatamente ao chat, para "não perder o raciocínio"; e, quando um tutor responde pelo atendimento, o outro opta por ignorar os pop-ups e dar continuidade à tarefa em curso.

Outra variável é a natureza dos assuntos discutidos no chat público, pois ela muda constantemente e não se limita apenas ao conteúdo das disciplinas. Após a análise dos textos de cada sessão de monitoração (40 horas) e a categorização de cada evento de interação em um conjunto de temas, encontrou-se a seguinte distribuição: em 126 eventos de interação (considerado aqui como cada diálogo entre o tutor e um aluno/instrutor), observou-se que não há a predominância de um tema, apontando para uma variabilidade significativa na natureza da atividade. Os temas mais discutidos estão relacionados às solicitações diversas $(23 \%$ solicita nota dos exercícios pedagógicos, nota em provas e marcação de provas) e ao conteúdo propriamente dito de cada disciplina (21\%), seguidos do envio ou da confirmação do recebimento dos exercícios pedagógicos respondidos, uma vez que estes são veiculados por meio do correio eletrônico (17\%); questões relacionadas ao suporte administrativo (17\%, apesar da escola disponibilizar um chat específico para a Secretaria) e temas com função socializante (8\%), em assuntos como festividades, acontecimentos do cotidiano, entre outros.

Além das demandas descritas, os tutores também acabam por tentar responder a um outro tipo de solicitação: a de caráter técnico, relacionada a questões de compatibilidade de aplicativos (8\%), apesar da escola oferecer um canal de comunicação entre os alunos e a equipe de suporte a hardware e software. Situações diversas foram encontradas $(6 \%)$, como por exemplo, a do aluno que interrompe o diálogo sem motivo aparente, não sendo possível identificar qual seria a natureza de sua demanda. 
É importante ressaltar que outros canais formais estão disponíveis para a requisição da maior parte desses serviços, pelos alunos. Apesar disto, há uma preferência, evidenciada pelos dados, pelo contato com o tutor. Duas explicações são plausíveis: a facilidade de obter rapidamente a resposta, pois há sempre um tutor à disposição, e uma identificação dos alunos com os tutores, devido ao contato freqüente. Considerando a natureza da demanda dos alunos é factível supor também que os outros canais disponibilizados pela organização não são efetivos, visto que 54\% dos eventos de interação estão relacionados a atividades que não fazem parte das tarefas dos tutores.

Segundo Sternberg (2000), quando existem tarefas interferentes e uma destas é automatizada, há uma tendência à redução da alocação de recursos para ela. Considerando que a capacidade de atenção é limitada, ela prioriza a recuperação rápida das representações relevantes para a realização da tarefa automatizada e a manutenção de recursos cognitivos para as tarefas em que há maior necessidade de controle. No caso dos tutores, os dados apontam uma grande variabilidade de assuntos, sendo que o tempo de resposta para cada um deles é determinado e que cada evento de interação é específico. Além da variabilidade nas categorias gerais de assuntos, a especificidade das demandas dificulta a automatização dos procedimentos, devendo o tutor analisar, de forma controlada, cada questão e as possíveis estratégias de solução. Essa situação exige do tutor a readaptação constante das representações para ação, a fim de adequá-las ao novo problema. Conceitualmente, as representações para ação não são cristalizadas (Teiger, 1993), modificando-se pela ação do sujeito. Contudo, há uma tendência em manter o padrão de ativação.

Com o intuito de ilustrar a dinâmica do trabalho dos tutores nessa organização, será apresentada uma crônica da atividade de monitoração, explicitando o impacto dos artefatos tecnológicos em sua atividade. 


\section{5 - A crônica da atividade de monitoração}

A atividade de monitoração do chat no período noturno, realizado pelo Tutor 4, é descrita na Figura 1, sendo enfocadas a checagem de emails (do primeiro ao $25^{\circ}$ minuto), o treinamento do Tutor 1 (do $48^{\circ}$ ao $54^{\circ}$ minuto) e o atendimento às demandas de alunos e instrutores, durante todo o período de observação. A ferramenta mais utilizada após o chat é o Gerenciador de e-mails (28 vezes), seguido do Navegador de Internet (24 vezes) e do Banco de dados (16 vezes). O Gerenciador de arquivos foi utilizado 12 vezes, o Editor de textos, cinco vezes, e a Planilha eletrônica utilizada três vezes. O back-up do conteúdo do chat foi efetuado apenas uma vez.

\section{FIGURA 1}

Representação gráfica da atividade monitoração, a partir das ferramentas utilizadas, executada pelo Tutor 4, no período da noite. Duração: 1 hora

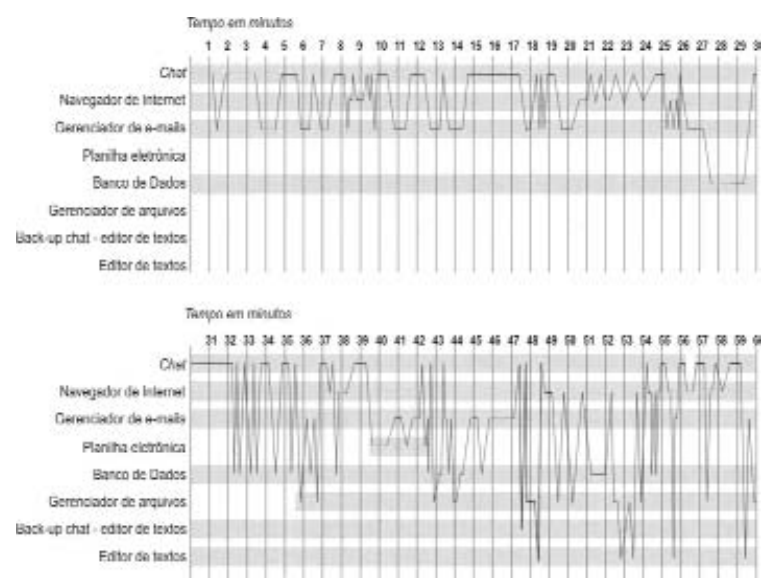

Para a checagem dos e-mails, o Tutor utiliza duas ferramentas: o Gerenciador de e-mails, para checar os e-mails vinculados à tutoria, e o Navegador de Internet, para visualizar os e-mails pessoais. 
Até o $25^{\circ}$ minuto, o Tutor atende um instrutor que deseja informações sobre cópia de atividades pedagógicas, checa os e-mails da tutoria e os e-mails pessoais. A partir do $26^{\circ}$ minuto, outra demanda se coloca: um instrutor solicita a situação acadêmica de um aluno, bem como os exercícios que lhe restam para finalizar uma disciplina. Para responder o Tutor utiliza o Banco de dados (buscando a Ficha Individual do aluno), o Gerenciador de e-mails (verificando as mensagens enviadas por esse aluno), o Gerenciador de arquivos (checando os arquivos enviados) e a Planilha eletrônica (formatando a tabela que deve ser enviada ao aluno por meio de gerenciador de e-mails), mantendo a atenção dividida entre o chat e as outras ferramentas. Esse procedimento se estende até o $47^{\circ}$ minuto, quando o Tutor salva uma cópia de segurança do chat e começa a transmitir informações de uma disciplina ao Tutor 1, que irá substituí-lo.

O sistema informatizado apresenta problemas ao final do $55^{\circ}$ minuto, obrigando o Tutor a fechar o chat e abri-lo novamente, para atender a uma nova demanda. As informações referentes ao período do último back-up e a nova abertura do chat foram perdidas.

Fica evidente, no decorrer da apresentação dos resultados, que o aparato tecnológico não só media a relação do tutor com as suas tarefas e a relação tutor-aluno, mas principalmente estrutura o seu trabalho. Assim, para cumprir suas atribuições, o tutor deve fazer uma gestão constante entre a diversidade e a imprevisibilidade inerentes ao trabalho e as ferramentas disponibilizadas. Essa gestão está diretamente relacionada à competência do tutor em interpretar as demandas, elaborar estratégias para respondê-las, alocar os recursos necessários, monitorar e avaliar as ações de forma a solucioná-las.

A noção de competência articula diferentes aspectos que influenciam a ação do indivíduo: a) os conhecimentos que ele possui, b) as representações para ação evocadas, c) as estratégias operatórias e d) a expertise (ou a experiência voltada a uma ação específica). Cada uma dessas 
dimensões pode determinar o sucesso ou o fracasso de uma ação e, em última instância, elas compõem a competência do tutor. Elas são vistas de forma integrada e a modificação em alguma delas interfere na qualidade da gestão da atividade.

O trabalho do tutor pode ser interpretado como um conjunto de problemas a serem resolvidos. Quanto mais o tutor conhece o estado inicial (problema) e o estado final (solução), bem como o conjunto das possibilidades de ação (espaço do problema), maior a probabilidade de êxito (Newell; Simon, 1972 apud Sternberg, 2000; Best, 1995, Anderson, 1993). Nas atividades dos tutores, verifica-se que essa condição pode não ocorrer. A imprevisibilidade favorece que alguns problemas colocados, em função do contexto, se apresentem como mal estruturados, ou seja, os tutores não identificam o estado final ou o caminho adequado para alcançá-lo. Algumas demandas (retiradas dos textos dos chats) dos alunos, como identificar o nome dos "bonequinhos pretos do Office", faz com que, segundo o Tutor 2: “ser tutor também é ser adivinho". Nesse caso, é necessário em primeiro lugar estruturar melhor o espaço do problema com o intuito de responder à demanda imposta.

Quando o tutor tem que atender mais de uma demanda ao mesmo tempo, ele evoca representações que não são compostas pelo somatório das representações que ele utiliza para responder a cada uma das demandas isoladamente. Alguns traços de conhecimento podem ser comuns às diferentes situações como, por exemplo, os procedimentos para a manipulação correta das ferramentas. Porém, eles se articulam com outros conhecimentos de maneira distinta. Como as representações para ação são modificadas a cada vez que o tutor age, sugerindo um processo de construção constante e não uma busca na memória de representações prontas, fixas, o que está em consonância com a idéia de Teiger (1993), espera-se que elas se tornem cada vez mais apropriadas a uma situação específica. Como a repetição de uma determinada ação leva a uma 
procedimentalização, automatização (Best, 1995; Sternberg, 2000), quanto mais o tutor atender a uma demanda específica, menos recursos essa demanda exige, e as representações que suportam a ação se tornam mais adaptadas. No entanto, a duplicidade no atendimento, a imprevisibilidade e a variabilidade das demandas elevam o número de situações novas, ou espaços de problemas diferentes, retardando o processo de automatização.

As estratégias operatórias adotadas pelos tutores se manifestam pelos seus modos operatórios, ou seja, pela sua ação. Nesse sentido, elas são processos de regulação que envolvem mecanismos cognitivos como categorização (reconhecimento de padrões), resolução de problemas e tomada de decisão (Silvino; Abrahão, 2003).

Os dados apresentados vão ao encontro do que Quesada et al. (2002) chamam de resolução de problemas complexos. Segundo os autores, os problemas fora do laboratório, pertencentes ao cotidiano, possuem características que os tornam complexos. Eles são dinâmicos, já que decisões anteriores interferem no atual contexto do problema, modificando-o sem a ação do sujeito. São circunscritos temporalmente, o que condiciona a resposta a uma limitação de prazo, e são não-lineares, o que leva o sujeito a ter que elaborar diferentes estratégias complementares para a resolução.

De fato, essas três características apontadas por Quesada et al. (2002) podem compor uma visão mais ampla do trabalho dos tutores. Todas elas fazem parte de um conjunto de elementos que influenciam as tarefas, elevando: a) o número de elementos a serem tratados; b) a interação entre esses elementos e a necessidade de gestão dessas interações; c) o grau de abstração exigido; d) a imprevisibilidade dos eventos e e) a exigência de antecipação e avaliação de possíveis disfuncionamentos. 
Os resultados obtidos neste estudo foram analisados na expectativa de evidenciar as relações do tutor com suas tarefas e ferramentas, bem como as estratégias utilizadas para executar suas tarefas. Para apontar tais estratégias, utilizadas para gerenciar a discrepância entre o trabalho prescrito e o real, é necessário compreender o impacto da natureza do trabalho para eles. A incerteza e a variabilidade são responsáveis por alguns efeitos demonstrados ao longo do estudo: a necessidade de antecipação constante, o aumento do custo para a elaboração de representações para ações mais adequadas, a exigência acentuada dos processos de codificação, armazenamento e evocação de informações na memória, a constante necessidade de dividir a atenção, a ocorrência de problemas mal estruturados e de tarefas concorrentes. Esses efeitos culminam nas estratégias operatórias descritas nesta subseção, permitindo que os tutores sejam capazes de desempenhar suas atribuições, respondendo às demandas dos alunos. Os dados das crônicas da atividade permitem evidenciar tais estratégias e inferir como se dá o processo de regulação no trabalho por parte dos tutores.

\section{Conclusão}

O presente estudo abordou o trabalho de uma equipe de tutores em uma escola privada que oferece cursos a distância. O papel do tutor é mediar a interação entre os instrutores, os alunos e as Escolas Licenciadas, bem como atender às diferentes demandas dos alunos. Em consonância com a discussão apresentada pela literatura em Ergonomia (Abrahão, 1993; Marmaras; Kontogiannis, 2001; Rasmussen, 2000), os resultados mostraram que as novas tecnologias impactam na atividade de quem ensina à distância, estruturando a relação dos tutores com o seu trabalho e com os alunos. Nesse sentido, compreender a dinâmica dos elementos que compõem a atividade é fundamental para a análise dos sistemas informatizados de mediação. 
Os resultados obtidos por meio da Análise Ergonômica permitem concluir que o trabalho estudado é caracterizado pela variabilidade das demandas dos alunos, quantidade e qualidade das ferramentas utilizadas, imprevisibilidade com relação à estabilidade do sistema e pressão temporal, exigindo dos tutores uma capacidade de antecipação constante e a elaboração de estratégias e modos operatórios que assegurem a realização do trabalho. Este estudo de caso permitiu desvendar algumas características da atividade do tutor e sua relação com as interfaces informatizadas, apontando para a necessidade de adaptar, de acordo com as necessidades dos trabalhadores e as características do trabalho, os artefatos informatizados.

Para responder quem é o tutor, é necessária uma análise mais ampla, relacionando a utilização de novas tecnologias na educação, em especial a informática e a Internet, com um novo paradigma educacional. Autores como Perrenoud (2000), Morin (1999) e Ramal (2002) enfocam essa mudança quando afirmam que é preciso uma nova visão de quem ensina, abordando o ensino e a aprendizagem como um processo de construção coletiva e aproximando esse processo da realidade em que a sociedade se encontra.

Sugere-se, em estudos futuros, que alguns aspectos sejam estudados com o objetivo de agregar resultados relevantes para a compreensão do trabalho dos tutores mediados por interfaces informatizadas: a) outros contextos de Educação a Distância pela Internet podem ser estudados, buscando verificar a generalidade das evidências aqui apresentadas; b) mais informações sobre o contexto onde o trabalho está inserido pode auxiliar na compreensão das exigências que o trabalho impõe aos tutores; c) por fim, sugere-se inserir o corpo discente no processo de análise, visando compreender mais adequadamente como se apresentam as demandas dos alunos, qual a fonte da sua variabilidade, da relevância do contato, mesmo que virtual com o tutor, e qual o papel do 
sistema informatizado na escolha dos canais de comunicação a serem preferencialmente utilizados pelos alunos.

A educação é a base da construção da cidadania e da inclusão social. Elaborar sistemas de ensino que ampliem o espectro de informações transmitidas à população, bem como aumentar o contingente de pessoas que possam usufruí-lo são, sem dúvida, ações relevantes. As inovações tecnológicas podem contribuir, e o fazem, para democratizar o acesso à informação. É relevante destacar, contudo, que a informática não só flexibiliza e intensifica o contato do aluno com o conhecimento, mas também traz consigo a necessidade de repensar o papel dos diferentes atores: aluno, professor, tutor e escola. Estudar essa dinâmica é tarefa de várias áreas do conhecimento, e seu aprimoramento possibilita cada vez mais a oferta de uma educação de qualidade para a sociedade.

\section{REFERÊNCIAS}

ABRAHÃO, Júlia Issy. Ergonomia, modelos, métodos e técnicas. In: CONGRESSO LATINO AMERICANO E VI SEMINÁRIO BRASILEIRO DE ERGONOMIA, 2, 1993, Florianópolis. Resumos, Florianópolis, SC, 1993.

ABRAHÃO, Júlia Issy; PINHO, Diana Lúcia Moura. Teoria e prática ergonômica: seus limites e possibilidades. In: PAZ, Maria das Graças Torres; TAMAYO, Álvaro (Org.). Escola, saúde e trabalbo: estudos psicológicos. Brasília: Ed. UnB, 1999. p. 229-239.

ABRAHÃO, Júlia Issy; PINHO, Diana Lúcia Moura. As transformações do trabalho e desafios teórico-metodológicos da ergonomia. Estudos de psicologia. 7. ed. especial. 2002, p. 45-52.

ABRAHÃO, Júlia Issy; SILVINO, Alexandre Magno Dias; SARMET, Mauricio Miranda. Ergonomia, cognição e trabalho informatizado. Psicologia: teoria e pesquisa, 21(2), p. 163-171, 2005. 
AMALBERTI, René. Savoir-faire de l'opérateur: aspects théoriques et pratiques en ergonomie. In: AMALBERTI, René; MONTMOLLIN, Maurice de; THEUREAU, Jacques (Ed.). Modèles en analyse du travail. Liège: Mardaga, 1991. p. 279-294.

ANDERSON, John R. Problem Solving and Learning. American Psychologist, 48(1), p. 35-44, 1993.

BELLONI, Maria Luiza. Educação a distância. Campinas, SP: Autores Associados, 1999.

BEST, John B. Cognitive Psychology. 5 ed. St. Paul, MN: West Publishing Company, 1995.

CAÑAS, José Juan; WAERNS, Yvonne. Ergonomía Cognitiva: Aspectos Psicológicos de la interacción de las personas con la tecnologia de la informacíon. Madrid: Editorial Medica Panamericana, 2001.

COIÇAUD, S. A colaboração institucional na educação a distância. In: LITWIN, Edith (Org.). Educação a distância: temas para o debate de uma nova agenda educativa. Porto Alegre: Artmed, 2001. p. 53-72.

FERREIRA, Mário César. Atividade, categoria central na conceituação de trabalho em ergonomia. Alethéia, 1(11), p. 71-82, 2000.

GUÉRIN, François; LAVILLE, Antoine; DANIELLOU, François; DURAFFOURG, J.; KERGUELEN, A. Compreender o trabalho para transformá-lo: a prática da ergonomia. Tradução de L. Sznelwar et al. São Paulo: Edgar Blücher, 2001 (original publicado em 1991).

HOLLNAGEL, Eric. Cognitive Ergonomics: It's all in the Mind. Ergonomics, 40(10), p. 1170-1182, 1997.

KEREN, G. On the importance of identifying the correct 'problem space'. Cognition, 16, p. 121-128. 1984.

LEPLAT, Jacques. Competénce et ergonomie. In: AMALBERTI, René; MONTMOLLIN, Maurice de; THEUREAU, Jacques (Ed.). Modèles en analyse du travail. Liège: Mardaga, 1991, p. 263-278.

LITWIN, Edith. Das tradições à virtualidade. In: LITWIN, Edith (Org.). 
Educação a distância: temas para o debate de uma nova agenda educativa. Porto Alegre: Artmed, 2001, p. 13-22.

MAIA, Carmen. Guia brasileiro de educação a distância 2002/2003. São Paulo: Esfera, 2002.

MAGGIO, M. O Tutor na Educação a Distância. In: LITWIN, Edith (Org.). Educação a distância: temas para o debate de uma nova agenda educativa. Porto Alegre: Artmed, 2001, p. 93-110.

MARINHO, S. P. Tecnologia, educação contemporânea e desafios ao professor. In: M. C. R. A. Joly (Org.). A tecnologia no ensino: implicações para a aprendizagem. São Paulo: Casa do Psicólogo, 2002. p. 41-62.

MARMARAS, N.; KONTOGIANIS, T. Cognitive Task. In: SALVENDY, Gavriel. Handbook of Industrial Engineering. New York: John Wiley \& Sons, 2001.

MARMARAS, N.; PAVARD, Bernard. Problem-Driven Approach to the Design of Information Technology Systems Supporting Complex Cognitive Tasks. Cognition, Technology \& Work, 1(4), p. 222-236. 1999.

MERCER, N; ESTEPA, F. G. A Educação a distância, o conhecimento compartilhado e a criação de uma comunidade de discurso internacional. In: LITWIN, Edith (Org.). Educação a distância: temas para o debate de uma nova agenda educativa. Porto Alegre: Artmed, 2001. p. 23-37.

MONTMOLLIN, Maurice de. L'intelligence de la tache. Toulouse: Octarés Éditions, 1986.

MONTMOLLIN, Maurice de. A ergonomia. Lisboa: Instituto Piaget, 1990. MONTMOLLIN, Maurice de. Vocabulaire de l'Ergonomie. Toulouse: Octarés Éditions, 1995.

MORAN, J. M. O que é educaşão a distância, 1999. Disponível em: $<$ http://www.eca.usp.br/prof/moran/textost.htm>. Acesso em: ago. 2002:

MORIN, Edgar. Os sete saberes necessários à educação do futuro. São Paulo: Cortez, 2001. 
PASHLER, H.; JOHNSTON, J.; RUTHRUFF, E. Attention and performance. Annual Review of Psychology, 52, p. 629-651, 2001.

PERRENOUD, P. Dez novas competências para ensinar. Porto Alegre: Artmed, 2000.

PRETTO, N. de L. Desafios para a educação na era da informação: o presencial, a distância, as mesmas políticas e o de sempre. In: BARRETO, R. G. (Org.). Tecnologias educacionais e educação a distância: avaliando políticas e práticas. Rio de Janeiro: Quartet, 2001. p. 29-53.

QUESADA, J. F.; CAÑAS, José Juan; ANTOLÍ, Adoración. In: WRIGHT, P.; DEKKER, S.; WARREN, C. P. (Ed.). ECCE-10: Confronting Reality. Sweden: EACE, 2000.

QUESADA, J. F; KINTSCH, W; GOMEZ, E. A Theory os Complex Problem Solving Using Latent Semantic Analysis. In: GRAY, W. D; SCHUNN, C. D. (Ed.). Proceedings of the 24th Annual Conference os the Cognitive Science Society. Mahwah, NJ: Fairfax, VA Lawrence Earbaum Associates, 2002. p. 750-755.

RAMAL, A. C. Educação na cibercultura. Hipertextualidade, leitura, escrita e aprendizagem. Porto Alegre: Artmed, 2002.

RASMUSSEN, J. Human factors in a dynamic information society: where are we heading? Egonomics, 43(7), p. 869-879. 2000.

SARMET, Mauricio Miranda. Análise ergonômica de tarefas cognitivas complexas mediadas por aparato tecnológico: quem é o tutor na educação a distância? 2003. Dissertação (Mestrado em Psicologia) - Universidade de Brasília, Brasília. 2003.

SHACKEL, B. People and computers: Some recent highlights. Applied Ergonomics, 31(6), p. 595-608. 2000.

SILVINO, Alexandre Magno Dias; ABRAHÃO, Júlia Issy. Navegabilidade e Inclusão digital: navegabilidade e competência. Revista de Administração de Empresas, RAE-Eletrônica. V2(2), 2003.

SILVINO, Alexandre Magno Dias. Ergonomia cognitiva e exclusão digital: a 
competência como elemento de (re)concepção de interfaces gráficas. 2004. 204 f. Tese (Doutorado em Psicologia) - Universidade de Brasília, Brasília.

STERNBERG, R. J. Psicologia cognitiva. Porto Alegre: Artmed, 2000.

TEIGER, Catherine. Représentation du travail, travail de la représentation. In: WEILL-FASSINA, A.; RABARDEL, P; DUBOIS, D. (Ed.). Représentation pour láction. Toulouse: Octarés Édition, 1993.

WEILL-FASSINA, A.; RABARDEL, P; DUBOIS, D. Représentations pour l'action. Toulouse: Octarés Éditions, 1993.

Recebimento: 18/10/2006

Aprovação: 10/09/2007

\section{Contato:}

Maurício Miranda Sarmet

SQN 313 - Bloco D, apto. 602

Brasília/DF - 70766-040 - Brasil

msarmet@gmail.com 